\title{
Activatable Rare Earth Near-Infrared-II Fluorescence Ratiometric Nanoprobes
}

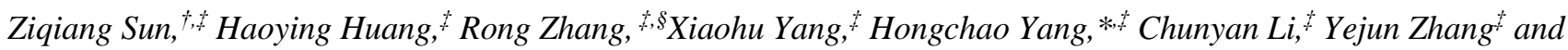
Qiangbin Wang $*+,+, s$

${ }^{\dagger}$ School of Nano-Tech and Nano-Bionics, University of Science and Technology of China, Hefei 230026, China

${ }^{*}$ CAS Key Laboratory of Nano-Bio Interface, Division of Nanobiomedicine and i-Lab, Suzhou Institute of Nano-Tech and Nano-Bionics, Chinese Academy of Sciences, Suzhou 215123, China

${ }^{\S}$ School of Physical Science and Technology, ShanghaiTech University, Shanghai 201210, China

\section{Experimental section}

\section{Materials}

Erbium (III) acetate hydrate (99.9\%), neodymium (III) acetate hydrate (99.9\%), sodium hydroxide (NaOH, 98\%), ammonium fluoride $\left(\mathrm{NH}_{4} \mathrm{~F}, 98 \%\right)$, octadecene (ODE,90\%), oleic acid (OA, 90\%), ovalbumin (OVA), complete Freund adjuvant (CFA) were purchased from Sigma-Aldrich. Poly(sodium-p-styrenesulfonate) (PSS) was purchased from Aladdin. Methanol (99.5\%), ethyl alcohol (99.7\%), cyclohexane (99.5\%), tetrahydrofuran (THF, 99\%) were purchased from Sinopharm Chemical Reagent Co., Ltd. (China). All other reagents were of analytical grade and used without further purification. 1,2-distearoyl-sn-glycero-3-phosphoethanolamine-N-[amino(polyethylene glycol)-2000] (DSPEPEG-NH $\mathrm{N}_{2}$ ) was purchased from NANOCS.

\section{Characterization}

The morphologies of the DSNPs were characterized by a Tecnai G2 F20 S-Twin TEM (FEI, USA) operated at $200 \mathrm{kV}$. Scanning TEM images in high-angle annular dark-field mode (HAADF-STEM) and element mappings were obtained in a Titan Themis Z (FEI, USA) operated at $300 \mathrm{kV}$, equipped with a probe aberration corrector to provide a spatial resolution below 1 Å. Powder X-ray diffraction (XRD) patterns were recorded on a Bruker D8 Advance powder X-ray diffractometer, using $\mathrm{Cu}-\mathrm{K} \alpha$ radiation $(\lambda=1.5406 \AA)$ in the range of $10^{\circ}-80^{\circ}$. The zeta potentials and hydrodynamic diameter (HD) of DSNPs and DSNP@A were measured using a Malvern Nanosizer. The absorption spectra were documented with Biomate 160 UV-vis-NIR spectrophotometer (ThermoFisher Scientific, USA). Fluorescence lifetime signals were collected for DSNPs samples dispersed in cyclohexane from FLS 980 (Edinburgh Instruments, UK). NIRII fluorescence imaging was performed with small animal imaging system (Suzhou NIR-Optics, China) equipped with a $1150 \mathrm{~nm}$ short-pass filter (SP 1150), a $900 \mathrm{~nm}$ long-pass filter (LP 900) and a $1300 \mathrm{~nm}$ long-pass filter (LP 1300).

\section{Preparation of shell precursors}

Y-OA precursor: The $\mathrm{YCl}_{3}(2.5 \mathrm{mmol}), \mathrm{OA}(10.0 \mathrm{~mL})$, and $\mathrm{ODE}(15.0 \mathrm{~mL})$ were put into a flask and heated at $140{ }^{\circ} \mathrm{C}$ under pumping with stirring for 1 hour to get rid of residual water and oxygen. Then the $0.10 \mathrm{M}$ Y-OA precursor solution was received.

Y:10\%Nd-OA precursor: $\mathrm{The}^{\mathrm{YCl}} \mathrm{Cl}_{3}(0.9 \mathrm{mmol}), \mathrm{OA}(4.0 \mathrm{~mL})$, and $\mathrm{ODE}(6.0 \mathrm{~mL})$ were put into in a flask and heated at $140{ }^{\circ} \mathrm{C}$ under pumping with stirring for 1 hour to get rid of residual water and oxygen. Then the $0.10 \mathrm{M} \mathrm{Y}: 10 \% \mathrm{Nd}-$ OA precursor solution was received.

Na-TFA-OA precursor: The Na-TFA-OA $(4.0 \mathrm{mmol})$ and $\mathrm{OA}(10.0 \mathrm{~mL})$ were put into in a flask at room temperature under pumping with stirring for 1 hour to get rid of residual water and oxygen. Finally, the $0.40 \mathrm{M} \mathrm{Na-TFA-OA}$ 
precursor solution was received.

\section{Synthesis core nanoparticles (NPs) of $\beta-\mathrm{NaErF}_{4}$}

The monodisperse $\mathrm{NaErF}_{4}$ NPs were prepared following a previously reported high-temperature co-precipitation method. ${ }^{1} 1.0 \mathrm{mmol}$ of $\operatorname{Er}(\mathrm{AC})_{3} \cdot, 6.0 \mathrm{~mL}$ of OA and $15.0 \mathrm{~mL}$ of ODE were contained in a $100 \mathrm{~mL}$ three-necked flask and heated to $130^{\circ} \mathrm{C}$ under pumping to obtain a clear solution, then cooled down to room temperature. Subsequently, a mixture of $10.0 \mathrm{~mL}$ of methanol, $5.4 \mathrm{mmol}$ of $\mathrm{NH}_{4} \mathrm{~F}$ and $2.5 \mathrm{mmol}$ of $\mathrm{NaOH}$ were injected into the reaction solution and stirred for $1 \mathrm{~h}$. Afterward, the reaction mixture was then heated to $100{ }^{\circ} \mathrm{C}$ and maintained for 30 min to remove the methanol and water. Finally, the solution was heated to $295^{\circ} \mathrm{C}$ and maintained for 60 min under a gentle $\mathrm{N}_{2}$ flow. The solution was cooled down to room temperature and the NP products were centrifuged, washed several times with ethanol, and dispersed in $5 \mathrm{~mL}$ of cyclohexane for further use.

\section{Synthesis of $\beta-\mathrm{NaErF}_{4} @ \mathrm{NaYF}_{4} @ \mathrm{NaYF}_{4}: x \% \mathrm{Nd} @ \mathrm{NaYF}_{4}$ core-shell NPs}

Briefly, $0.5 \mathrm{mmol}$ of $\mathrm{NaErF}_{4}$ core NPs were added three-neck flask containing $4.0 \mathrm{~mL}$ of OA and $6.0 \mathrm{~mL}$ of ODE. The solution was pumped down at $80{ }^{\circ} \mathrm{C}$ for $30 \mathrm{~min}$ to remove cyclohexane. ${ }^{2} \mathrm{Then}$, the system was heated to $280{ }^{\circ} \mathrm{C}$ under the $\mathrm{N}_{2}$ flow with vigorous stirring for $20 \mathrm{~min}$. Subsequently, the $1.0 \mathrm{ml}$ of Y-OA and $0.5 \mathrm{~mL}$ of Na-TFA-OA precursors were injected the above solution maintained for $15 \mathrm{~min}$ respectively. As for the doping $\mathrm{Nd}$, repeat the above-mentioned process but replace the Y-OA with Y:x\%Nd-OA. The shell thickness was tuned by the injection times. Finally, the resulting NPs were precipitated by addition of ethanol, and redispersed in cyclohexane.

\section{Synthesis of phospholipids-capped DSNPs ( NH$_{2}$-PEGylated DSNPs)}

To make these NPs hydrophilic, we cladded the surface of NPs with a monolayer of functional phospholipids. 10 mg DSNPs and $50 \mathrm{mg}$ DSPE-PEG-NH 2 were dispersed in THF solution. Then, the mixture of DSNPS and DSPE-PEG$\mathrm{NH}_{2}$ was added into $10 \mathrm{~mL}$ deionized water by ultrasound $(30 \mathrm{~W})$ for $5 \mathrm{~min}$, followed by ultrafiltration three times (4500 $\mathrm{rpm} / \mathrm{min})$.

\section{Synthesis of PSS-capped DSNP (NH2-PEGylated DSNPs@PSS)}

To ensure $\mathrm{NH}_{2}$-PEGylated DSNPs could bind with A1094, PSS was used to coat on the surface of $\mathrm{NH}_{2}-\mathrm{PEGylated}$ DSNPs. Firstly, $2 \mathrm{mg}$ of PSS was dissolved in $10 \mathrm{~mL}$ of deionized water. Then, the PSS solution was added to DSNPs solution by ultrasound $(30 \mathrm{~W})$ for $5 \mathrm{~min}$, followed by ultrafiltration three times $(4500 \mathrm{rpm} / \mathrm{min})$.

\section{Synthesis of A1094}

The NIR absorber A1094 was synthesized according to previously reported methods. ${ }^{3}$ In a typical synthetic process, phloroglucinol and diisobutylamine (1:1, molar ratio) were added to prepare 5-(N, N-diisobutylamino)-1,3-benzenediol under azeotropic reflux in dry $\mathrm{N}_{2}$ for $6 \mathrm{~h}$ (yield 92\%). Then the column chromatograph purified 5-(N, Ndiisobutylamino)-1,3-benzenediol was condensed with croconic acid (2:1, molar ratio) to obtain A1094 (yield 7.5\%). MS (ESI, m/z) [(M+Na) $\left.{ }^{+}\right]$: Calcd for $\mathrm{C}_{33} \mathrm{H}_{42} \mathrm{~N}_{2} \mathrm{O}_{7}$ : 601.2992; found: 601.2882. ${ }^{1} \mathrm{H}$ NMR (400 MHz, $\mathrm{CDCl}_{3}, \delta$ ): 13.92 (s, 2H, OH), 6.10 (s, 2H, Ar H), 5.91 (s, 2H, Ar H), 3.39 (s, 8H, NCH2), 2.17 (m, 4H, CH), $1.00(\mathrm{~d}, \mathrm{~J}=6.58 \mathrm{~Hz}, 24 \mathrm{H}$, $\left.\mathrm{CH}_{3}\right) .{ }^{13} \mathrm{C} \mathrm{NMR}\left(100 \mathrm{MHz}, \mathrm{CDCl}_{3}\right) \delta: 165.55\left(\mathrm{~s}, \mathrm{C}-\mathrm{O}^{-}\right) 159.71(\mathrm{~s}, \mathrm{C}=\mathrm{O}), 157.04\left(\mathrm{~s}, \mathrm{C}_{\mathrm{arom}}-\mathrm{O}\right), 156.91\left(\mathrm{~s}, \mathrm{C}_{\mathrm{arom}}-\mathrm{N}\right)$, 119.99 (s, C=C), 95.96 (s, 2C, $\left.\mathrm{C}_{\mathrm{arom}}\right), 90.56$ (s, 4C, $\left.\mathrm{C}_{\mathrm{arom}}\right), 61.19\left(\mathrm{~s}, \mathrm{NCH}_{2}\right), 28.53(\mathrm{~s}, \mathrm{CH}), 20.17\left(\mathrm{~s}, \mathrm{CH}_{3}\right)$.

\section{Attachment of A1094 molecular to DSNPs (DSNP@A)}

A1094 molecules could be attached to the surface of the NPs via strong ionic bonding between quaternary ammonium salt and sulfonate groups. A1094 $(0.1 \mathrm{mg} / \mathrm{mL})$ was added into the as-prepared NPs in PBS under ultrasound. Finally, end product was obtained by ultrafiltration and washed with PBS solution three times, then final product DSNP@A was obtained. Loading efficiency (\%) was calculated as follows: 
Loading efficiency $=[$ amount of A1094 in the DSNPs] $/$ [total amount of A1094 used $] \times 100 \%$

\section{Preparation of ROS/RON solution}

$10 \mathrm{mM} \mathrm{ClO}^{-}$and $\mathrm{H}_{2} \mathrm{O}_{2}$ solutions were obtained through directly diluting the purchased standard solution, respectively. ${ }^{1} \mathrm{O}_{2}$ solution was generated from a mixed reaction of $\mathrm{NaMoO}_{4}(10 \mathrm{mM})$ and $\mathrm{H}_{2} \mathrm{O}_{2}(10 \mathrm{mM})$. Hydroxylradical $(\cdot \mathrm{OH})$ was obtained based on Fenton reaction by adding ferrous chloride $\left(\mathrm{FeCl}_{2}\right)$ into10 equiv. of $\mathrm{H}_{2} \mathrm{O}_{2}$ solution. Peroxynitrite (ONOO-) solution was obtained as follows. A mixture of $\mathrm{H}_{2} \mathrm{O}_{2}(0.7 \mathrm{M})$ and $\mathrm{NaNO}_{2}(0.6 \mathrm{M})$ was first prepared, and $\mathrm{HCl}$ $(0.6 \mathrm{M})$ was added into the above solution, followed by a $\mathrm{NaOH}(1.5 \mathrm{M})$ solution. A standard elution process was conducted to remove excess $\mathrm{H}_{2} \mathrm{O}_{2}$ by using a short column of manganese dioxide. The concentration of $\mathrm{ONOO}^{-}$was determined with a standard extinction coefficient of $\mathrm{ONOO}^{-}$in $0.1 \mathrm{M} \mathrm{NaOH}$ solution of $1670 \mathrm{M}^{-1} \mathrm{~cm}^{-1}$ at $302 \mathrm{~nm}$.

\section{The calculation of detection limit}

The calculation of detection limit (LOD) was based on the linear relationship between standard deviation of instrument and the slope of fitting response curve.

The LOD of DSNP@A is calculated according to the following equation:

$$
\mathrm{LOD}=\mathrm{k} \mathrm{s} / \mathrm{S}
$$

where $\mathrm{s}_{\mathrm{B}}$ and $\mathrm{S}$ are the standard deviation of instrument and the slope of fitting curve, respectively. The factor $\mathrm{k}$ is defined as 3 by IUPAC to avoid problems about the choice and validity of confidence limits. Thus, the value of $\mathrm{s}_{\mathrm{B}}$ is measured as 0.047 , while the $S$ value of the fitted curve is 0.178 obtained from the linear regression analysis, and the detection limit was calculated to be $0.8 \mu \mathrm{M}$.

\section{Cytotoxicity Assay}

The in vitro cytotoxicity study was performed by using a methyl thiazolyl tetrazolium (MTT) method. Briefly, L929 and U87 cells both were cultured in a RPMI 1640 medium supplemented with 10\% fetal bovine serum (FBS) and 1\% streptomycin and penicillin (S-P), and maintained in 5\% direct heat Autoflow $\mathrm{CO}_{2}$ air-jacketed incubators at $37{ }^{\circ} \mathrm{C}$. The cells were firstly plated in 96-well plates at a density of 8000-10000 cells per well, cultured overnight, and then incubated with $200 \mu \mathrm{L}$ of fresh cell media containing 0,62.5, 125, 250 and $500 \mu \mathrm{g} / \mathrm{mL}$ of DSNPs@A for $48 \mathrm{~h}$, respectively.

\section{Modeling of rheumatoid arthritis (RA) in mice}

All animal procedures were in agreement with the guidelines of Chinese Regulations for the Administration of Affairs Concerning Experimental Animals. Six-week old female athymic mice were obtained from Shanghai SLRC Laboratory Animal Co. Ltd. and maintained on a standard diet at room temperature. After adaptive feeding for a week, mice were induced by OVA to establish RA model as described by Wollheim et al. ${ }^{4}$ In detail, OVA solution at a concentration of $20.0 \mathrm{mg} / \mathrm{mL}$ was prepared with saline, mixed with equal volume of CFA, and then sufficiently emulsified at $4{ }^{\circ} \mathrm{C} .0 .1$ $\mathrm{mL}$ of above mixture was subcutaneously injected into three parts between the scapular region of mouse, and two additional immunizations were performed to strengthen the immune response in the same method every three days. Arthritis was induced at the ninth day by injecting $0.1 \mathrm{ml}$ of emulsified mixture including into the articular cavity. Four hours later, the articular cavity of sensitized mice was injected $25 \mu \mathrm{L}$ DSNP@A ( 1.7 mg and 14 nmol), and thereafter imaged by a homebuilt NIR-II fluorescence imaging system.

\section{In vivo fluorescence imaging of mice}

In vivo NIR-II fluorescence imaging was carried out by using NIR-II In Vivo Imaging System (Series II 900/1700, Suzhou NIR-Optics Technologies Co., Ltd., China). A zoom lens assembly (Navitar 6000) was used to achieve high spatial resolution. $2 \mathrm{~L} / \mathrm{min}$ oxygen flow with $2 \%$ isoflurane was used for anesthesia of the mice during injection and 
imaging. The mice were imaged at different time points postinjection using NIR-II fluorescence imaging system. The excitation light was provided by an $808 \mathrm{~nm}$ diode laser with a power density at the imaging plane of $60 \mathrm{~mW} \mathrm{~cm}^{-2}$. The $900 \mathrm{~nm}$ long-pass filter and $1150 \mathrm{~nm}$ short-pass filter were employed to collect the fluorescent signals at $1060 \mathrm{~nm}$, while the 1400-nm long-pass filter was employed for collecting the fluorescent signals at $1525 \mathrm{~nm}$. 


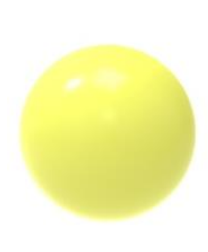

$\mathrm{NaErF}_{4}$

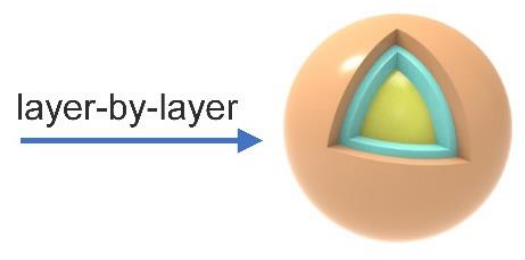

Er@Y@Nd layer-by-layer

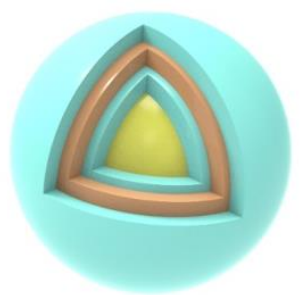

DCNPs

Figure S1. Schematic of the preparation of the $\mathrm{NaErF}_{4} @ \mathrm{NaYF}_{4} @ \mathrm{NaYF}_{4}: 10 \% \mathrm{Nd} @ \mathrm{NaYF}_{4} \mathrm{DSNPs}$ (donated as $\mathrm{NaErF}_{4} @ \mathrm{~B} @ \mathrm{NaYF}_{4}: 10 \% \mathrm{Nd} @ \mathrm{P}$; B: buffer layer of $\mathrm{NaYF}_{4}$; P: passivation layer of $\mathrm{NaYF}_{4}$ ) by successive layer-by-layer method.Er@Y@Nd means $\mathrm{NaErF}_{4} @ \mathrm{NaYF}_{4} @ \mathrm{NaYF}_{4}: 10 \% \mathrm{Nd}$. Hexagonal phase $\mathrm{NaErF}_{4}$ core was firstly synthesized to produce NIR-II light centered at $1525 \mathrm{~nm}$ via radiative relaxation from the first $\mathrm{Er}^{3+}$ excited state $\left({ }^{4} \mathrm{I}_{13 / 2}\right)$ to the ground state $\left({ }^{4} \mathrm{I}_{15 / 2}\right)$. Subsequently, an inert interlayer of $\mathrm{NaYF}_{4}$ was imported as the first shell to manipulate the distance between $\mathrm{Er}^{3+}$ and $\mathrm{Nd}^{3+}$, following by growing a thin $\mathrm{NaYF}_{4}: 10 \% \mathrm{Nd}$ active layer to generate $1060 \mathrm{~nm}$ NIR-II fluorescence. Finally, a passive $\mathrm{NaYF}_{4}$ coating at the outermost layer was applied to minimize the surface quenching effects.

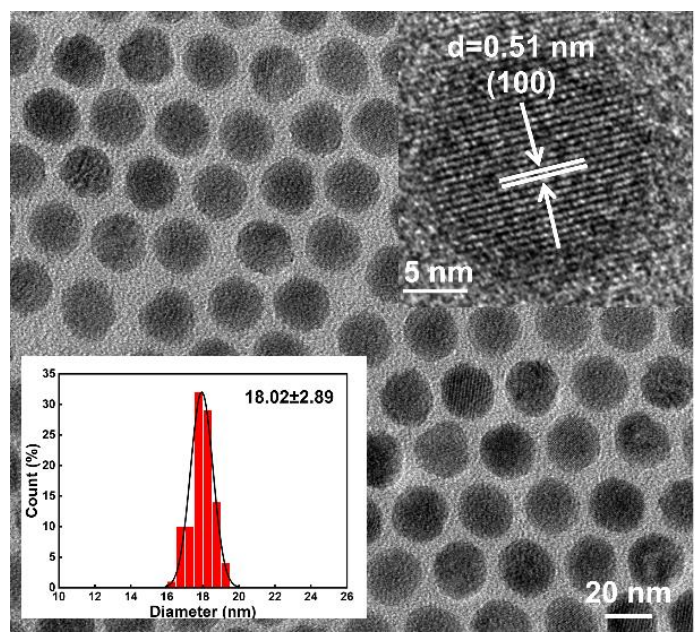

Figure S2. TEM images of $\mathrm{NaErF}_{4}$ core. Insets show the size distribution and HRTEM images of core NPs. 


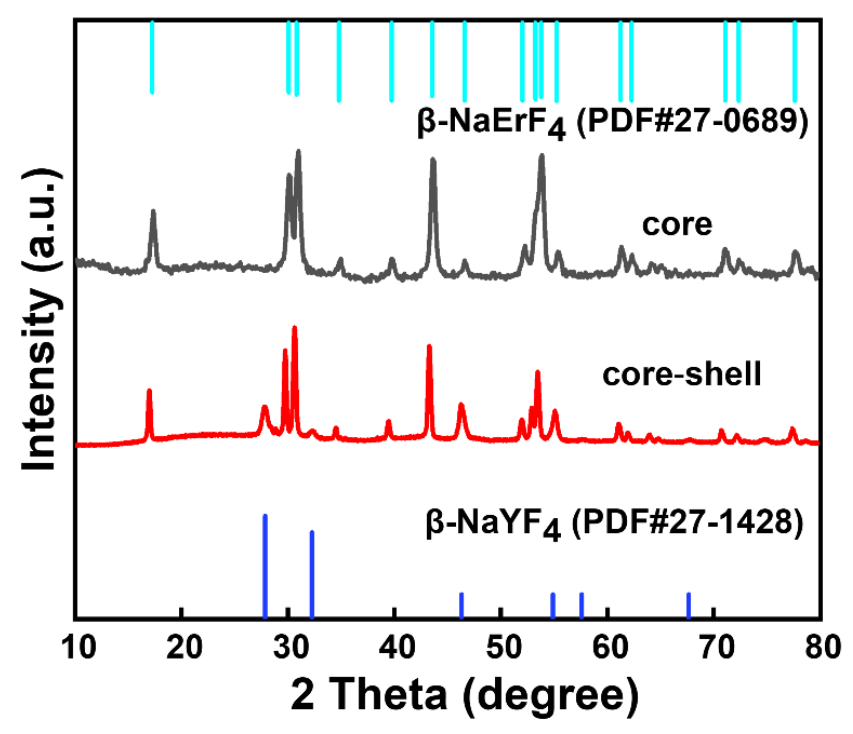

FigureS3: XRD patterns of core NPs and DSNPs films.

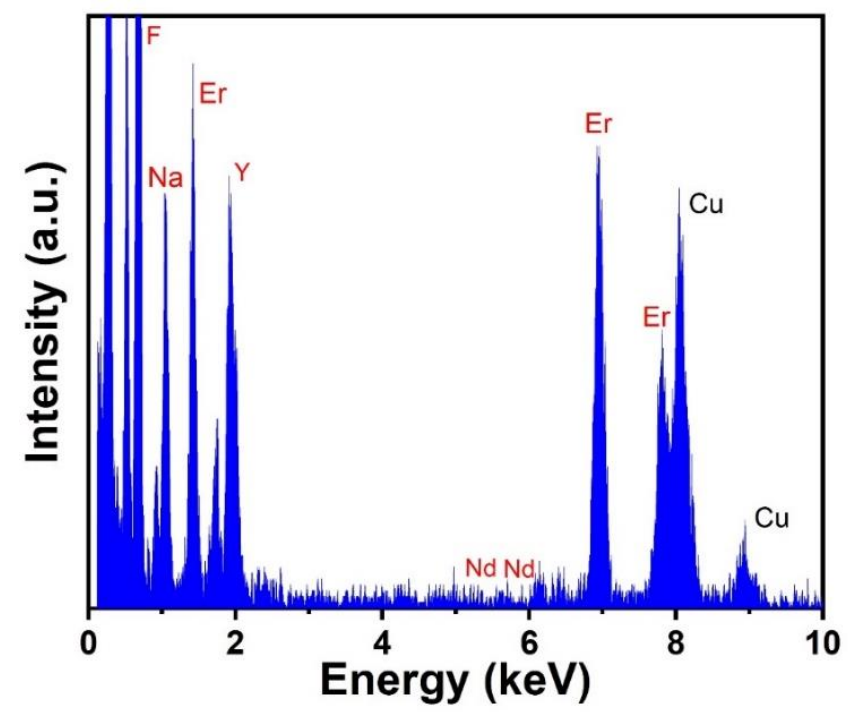

Figure S4. EDS spectrum of $\mathrm{NaErF}_{4} @ \mathrm{~B} @ \mathrm{NaYF}_{4}: 10 \% \mathrm{Nd} @ \mathrm{P}$. The Cu signal was originated from the carbon-coated copper grid substrate. 


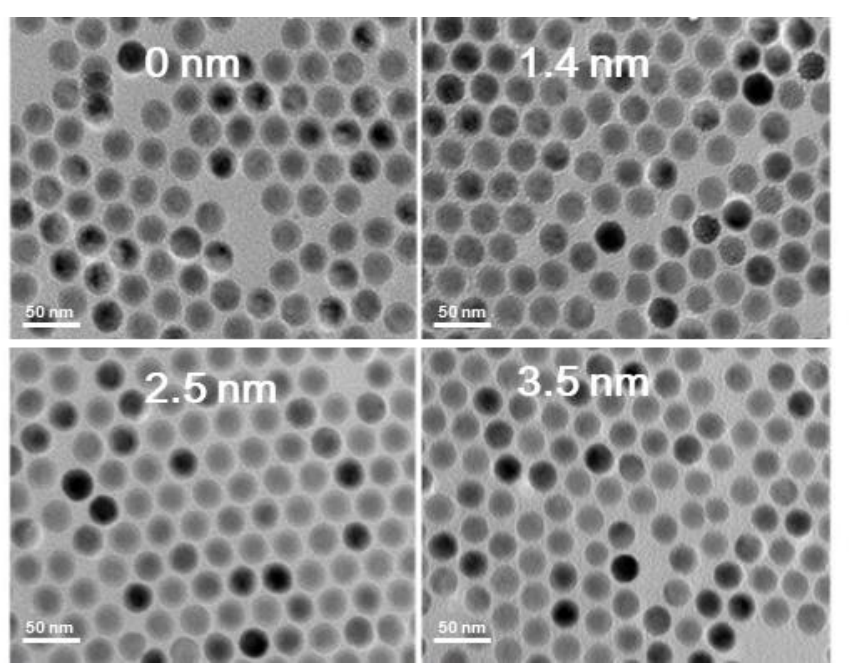

Figure S5. TEM images of $\mathrm{NaErF}_{4} @ \mathrm{~B} @ \mathrm{NaYF}_{4}: 10 \% \mathrm{Nd} @ \mathrm{P}$ with different buffer layer thicknesses $\left(d_{1}\right)$. The value of $d_{1}$ in these samples was $0,1.4,2.5,3.5 \mathrm{~nm}$, while the total thickness of the shell and $\mathrm{Nd}^{3+}$ content in these $\mathrm{NaErF}_{4} @ \mathrm{~B} @ \mathrm{NaYF}_{4}: 10 \% \mathrm{Nd} @ \mathrm{P}$ remained constant.
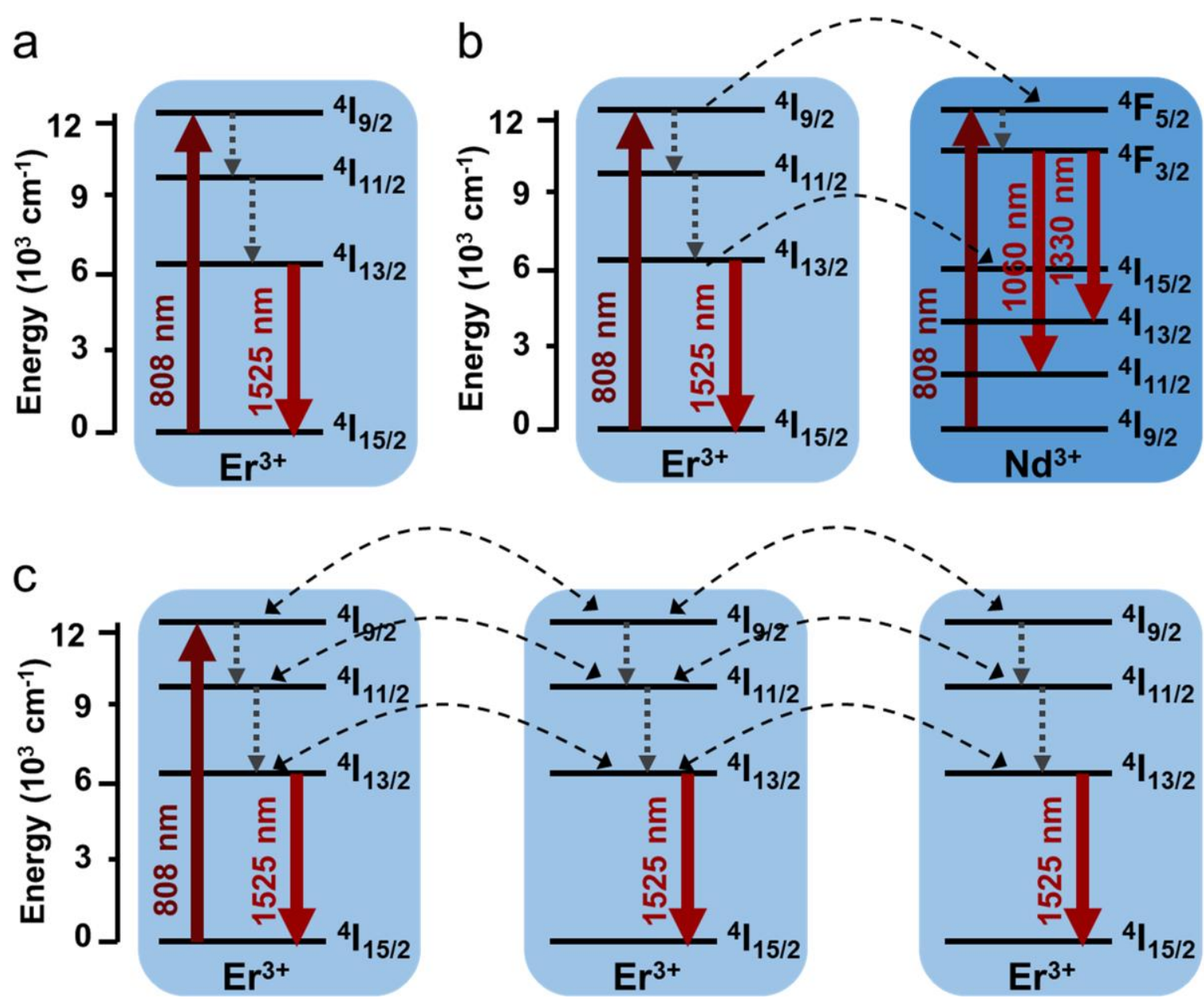

Figure S6. The possible energy transfer processes involved in the emission of $\mathrm{Er}^{3+}$ in $1525 \mathrm{~nm}$. (a) The relaxation process of $\mathrm{Er}^{3+}$ self-relaxation. (b) Er-Nd and (c) Er-Er cross-relaxation (CR) processes. 


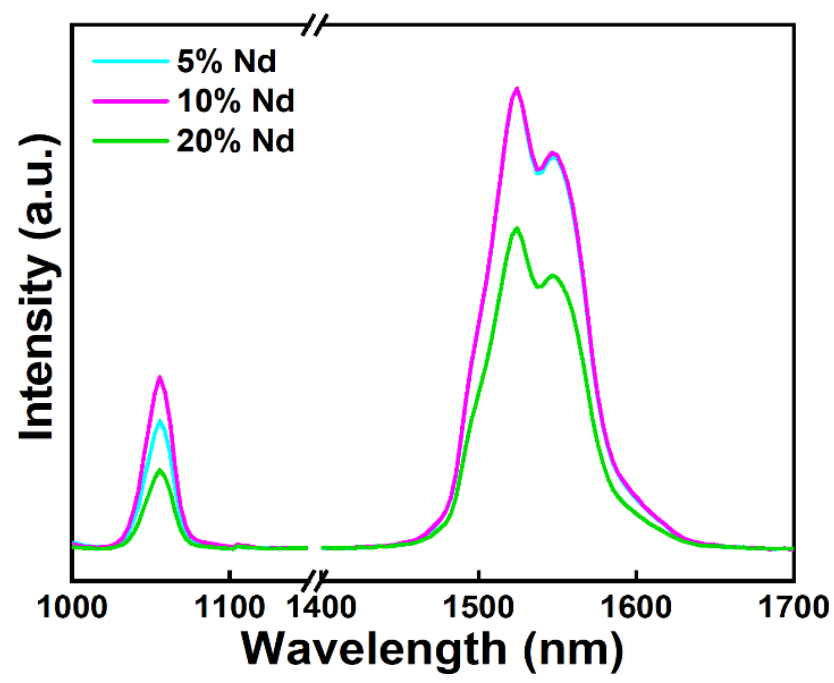

Figure S7. PL spectra of the same core-shell sized $\mathrm{NaErF}_{4} @ \mathrm{~B} @ \mathrm{NaYF}_{4}: \mathrm{X} \% \mathrm{Nd} @ \mathrm{P}$ doped with different $\mathrm{Nd}^{3+}$ concentrations.
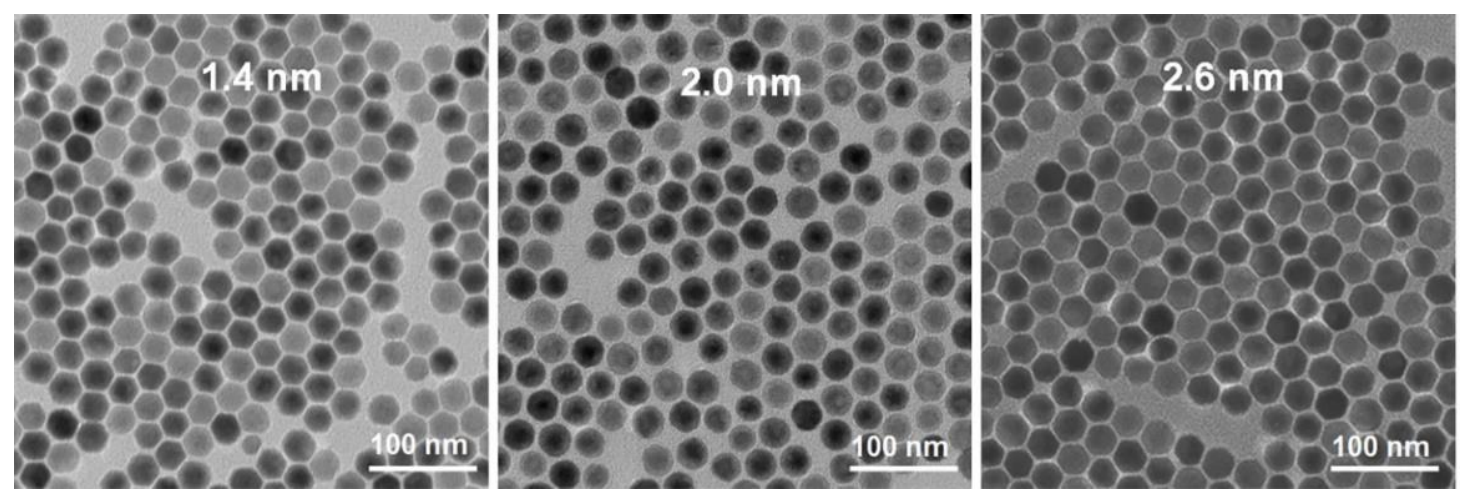

Figure S8. TEM images of $\mathrm{NaErF}_{4} @ \mathrm{~B} @ \mathrm{NaYF}_{4}: 10 \% \mathrm{Nd} @ \mathrm{P}\left(d_{1}=3.5 \mathrm{~nm}\right)$ with different thicknesses of $\mathrm{NaErF}_{4}$ passivation layer $\left(d_{2}\right)$.

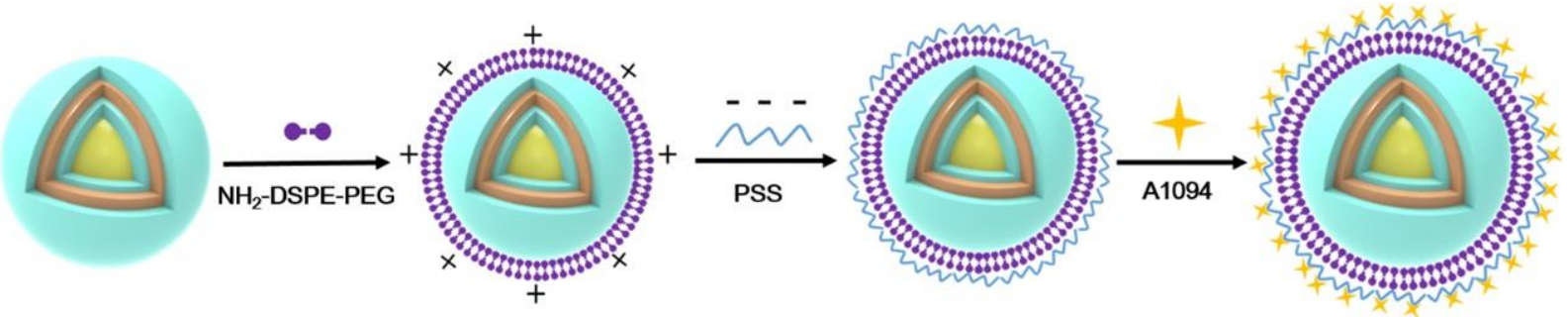

Figure S9.Schematic illustration of the synthesis of $\mathrm{NaErF}_{4} @ \mathrm{~B} @ \mathrm{NaYF}_{4}: 10 \% \mathrm{Nd} @ \mathrm{P} @ \mathrm{~A} 1094$ probe (termed as DSNP@A). The ratiometic DSNP@A was mainly composed of DSNPs and a NIR quencher of A1094, which had a strong absorption peak ranging from 1000-1200 nm. In order to conjugate A1094 and enhance physiological stability of DSNPs, DSPE-PEG-NH $\mathrm{N}_{2}$ was modified on the surface of DSNPs. Following the negatively charged PSS was attached onto the surface of $\mathrm{NH}_{2}$-PEGylated DSNPs by electrostatic interaction. Subsequently, PSS with abundant sulfonate groups could bind with A1094 via strong ionic bonding between sulfonate groups and quaternary ammonium to ensure the immobilization of A1094 on the surface of DSNPs. 

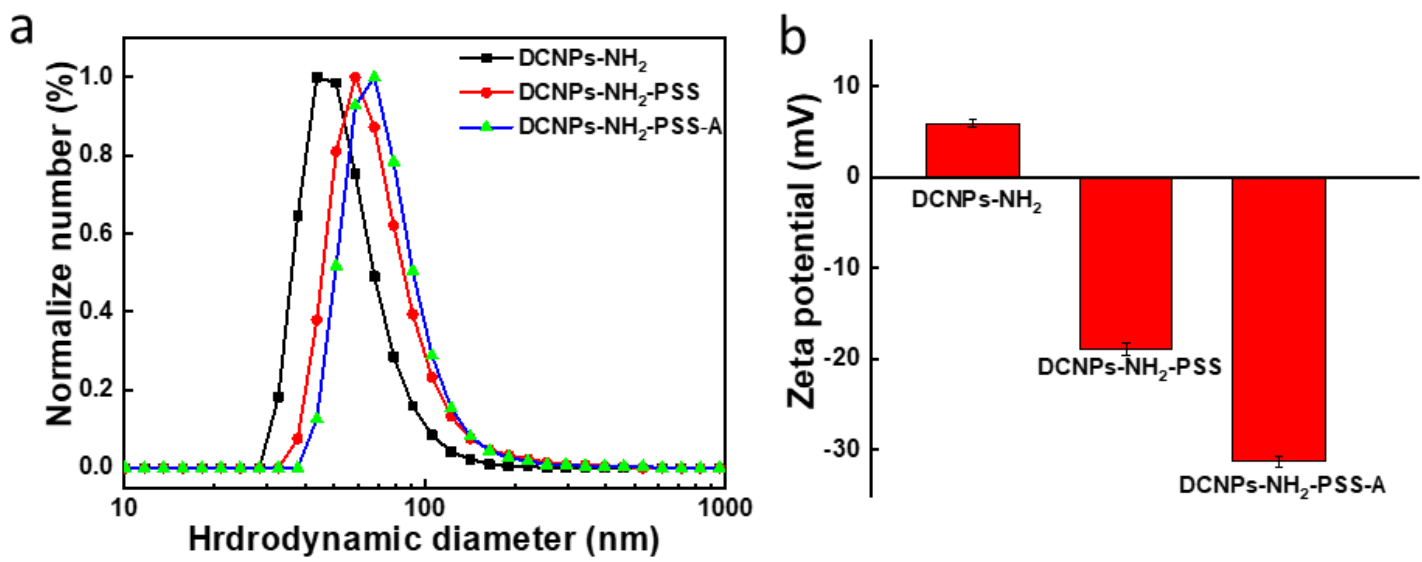

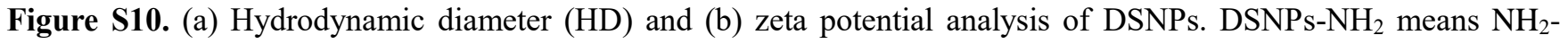
PEGylated DSNPs. DSNPs-NH $\mathrm{N}_{2}$-PSS means $\mathrm{NH}_{2}$-PEGylated DSNPs@PSS. DSNPs-NH 2 -PSS-A means DSNP@A. After coated with DSPE-PEG-NH $\mathrm{N}_{2}$, the oleic-capped DSNPs were transferred to aqueous and the $\mathrm{NH}_{2}-\mathrm{PEGylated}$ DSNPs showed a hydrodynamic diameter (HD) of $\sim 40 \mathrm{~nm}$ measured by the dynamic light scattering (DLS) measurement. After combining with A1094, the hydrodynamic diameter of DSNP@A increased to $70 \mathrm{~nm}$ compared to $\mathrm{NH}_{2^{-}}$ PEGylated DSNPs@PSS with hydrodynamic diameter $\sim 55 \mathrm{~nm}$. The zeta potential of the NPs was decreased from +5.9 $\mathrm{mV}$ for $\mathrm{NH}_{2}$-PEGylated DSNPs to $-18.8 \mathrm{mV}$ for that of DSNPs- $\mathrm{NH}_{2}-\mathrm{PSS}$ and then decreased to $-31.3 \mathrm{mV}$ after surface attachment of A1094.
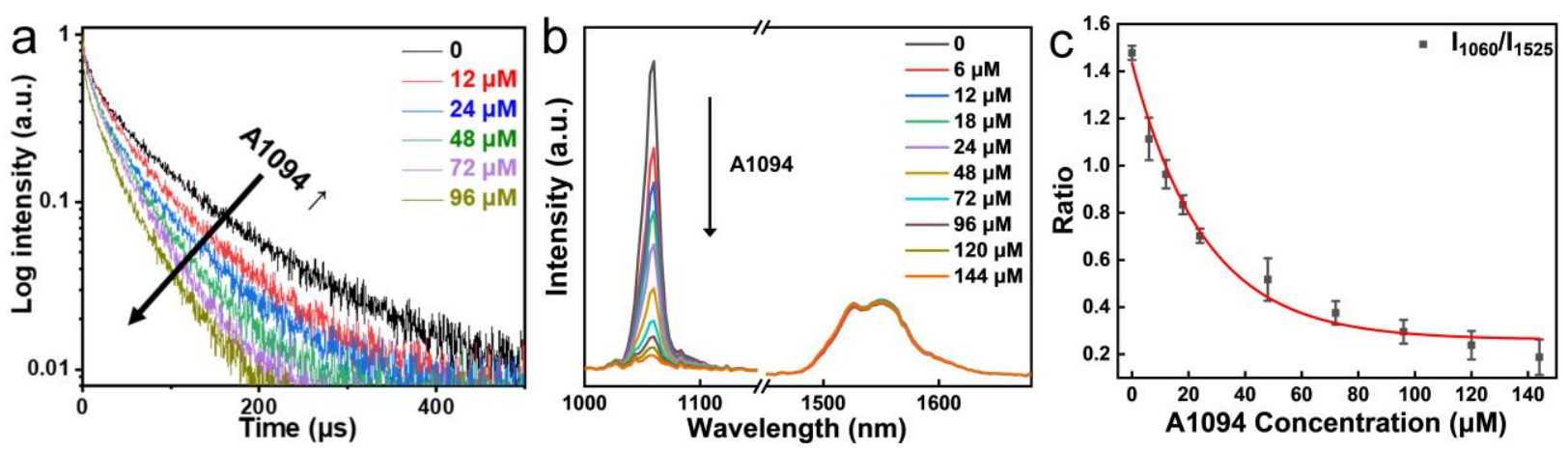

Figure S11. (a) PL decay curves of $\mathrm{Nd}^{3+}\left({ }^{4} \mathrm{~F}_{3 / 2} \rightarrow{ }^{4} \mathrm{I}_{11 / 2}\right)$ and (b) PL spectra of DSNP $\left(2 \mathrm{mg} \mathrm{mL}^{-1}\right)$ in PBS with different concentrations of A1094 excited by $808 \mathrm{~nm}(0-144 \mu \mathrm{M})$. (c) Plot of fluorescence ratio $\left(I_{1060 \mathrm{~nm}} / I_{1525} \mathrm{~nm}\right)$ changes as a function of A1094 concentration $(0-144 \mu \mathrm{M})$. As shown in Figure S11a, with the augment of bound A1094 from 0 to 94 $\mu \mathrm{M}$ in DSNP@A, the lifetime of $\mathrm{Nd}^{3+}$ in $1060 \mathrm{~nm}$ emission decreased continuously from 120 to $38 \mu \mathrm{s}$. Need to note, when more A1094 was conjugated onto the surface of DSNP, the luminescence at $1060 \mathrm{~nm}$ was severely quenched, resulting in its luminescence intensity being too weak to be captured by the instrument, which made it difficult to detect its lifetime. Meanwhile, the luminescence at $1060 \mathrm{~nm}$ was gradually quenched as A1094 was conjugated onto the surface of DSNP (Figure S11b). Moreover, the optimized loading concentration of A1094 was $144 \mu \mathrm{M}$ in $2 \mathrm{mg} \mathrm{mL}^{-1} \mathrm{DSNPs}$, which resulted in the favorable quenching efficiency of $\mathrm{Nd}^{3+} 1060 \mathrm{~nm}$ fluorescence (ca.92.5\%). Thus, based on the lifetime and luminescence intensity decay of $\mathrm{Nd}^{3+}$ after binding A1094, the energy transfer process between A1094 and DSNPs was confirmed as FRET. 


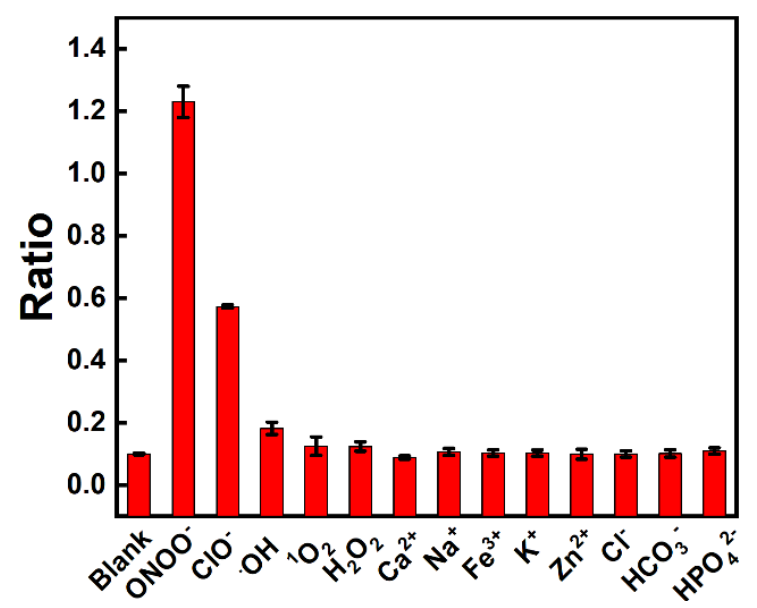

Figure S12. Fluorescence ratio changes $\left(I_{1060 \mathrm{~mm}} / I_{1525} \mathrm{~nm}\right)$ of DSNP@A $\left(2 \mathrm{mg} \mathrm{mL}^{-1}\right)$ in the presence of various ROS / RNS analytes and ions at $10 \mu \mathrm{M}$. To examine the specificity of DSNP@A, its response to various potentially interfering ROS/RON species was recorded, and the fluorescence ratio indicated that the nanoprobe had the most sensitive response to $\mathrm{ONOO}^{-}$compared with $\mathrm{ClO}^{-},{ }^{1} \mathrm{O}_{2}, \mathrm{H}_{2} \mathrm{O}_{2}$, $\cdot \mathrm{OH}$. In addition, other predominant physiological ions, including $\mathrm{Ca}^{2+}, \mathrm{Na}^{+}$, $\mathrm{Fe}^{3+}, \mathrm{K}^{+}, \mathrm{Zn}^{2+}, \mathrm{Cl}^{-}, \mathrm{HCO}_{3}{ }^{-}$and $\mathrm{HPO}_{4}{ }^{2-}$, exhibited negligible influence on the ratio of probe.
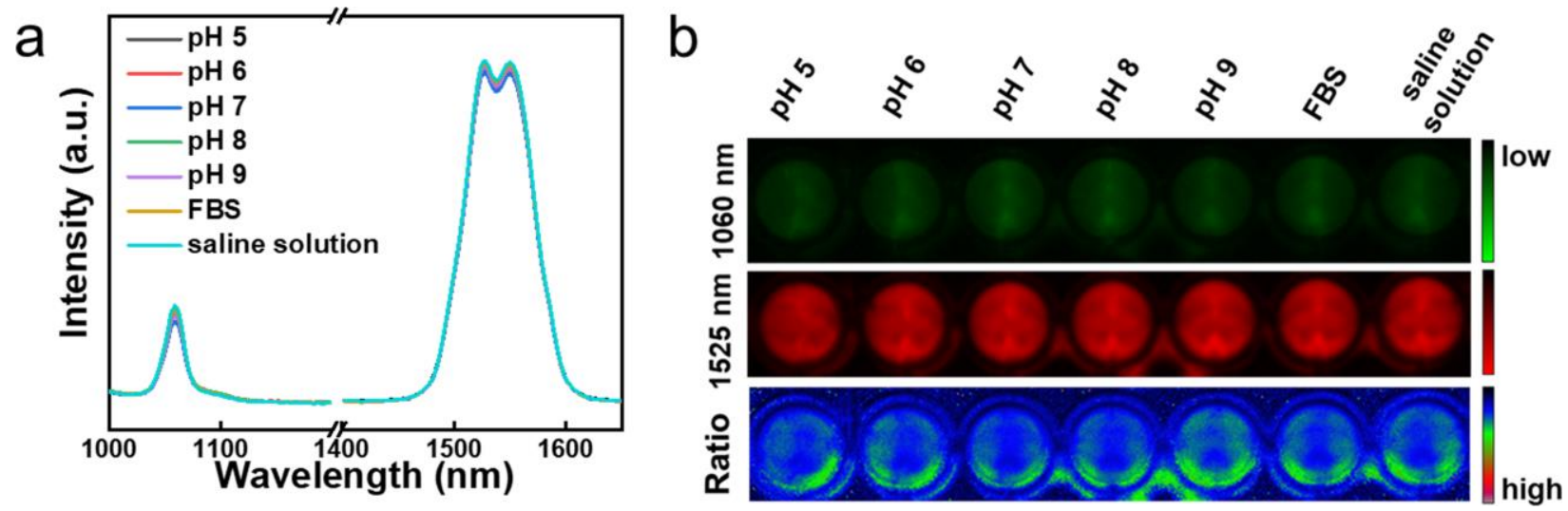

Figure S13. (a) PL spectra and (b) fluorescence images of DSNP@A in different pH buffer, FBS and saline solution. 

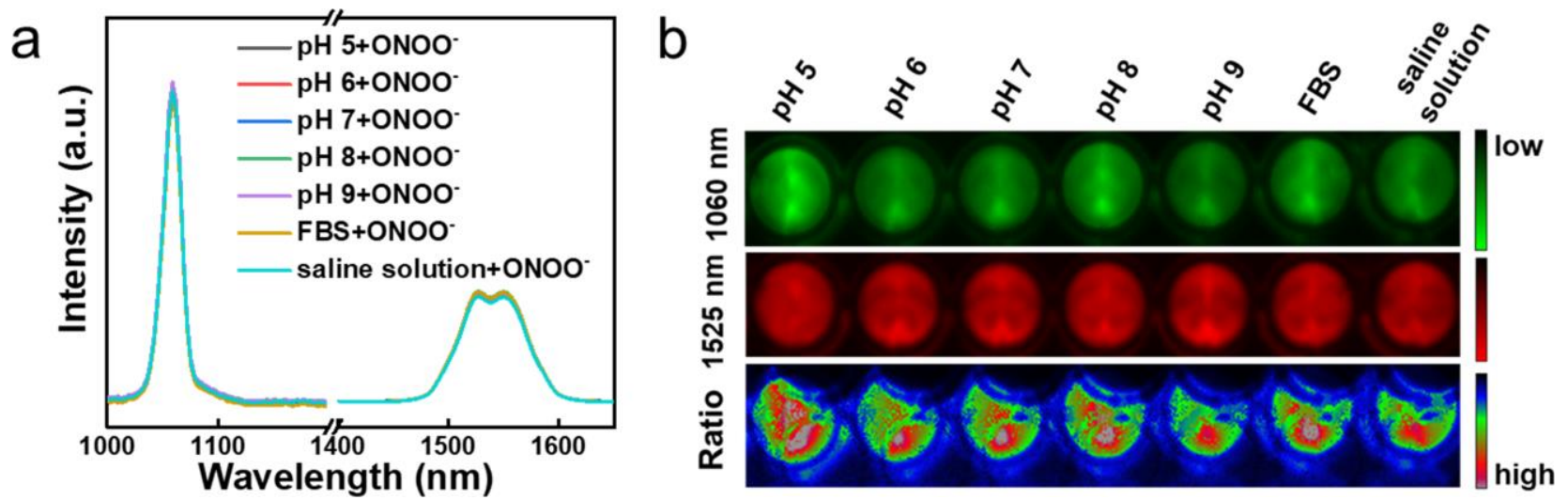

Figure S14. (a) PL spectra and (b) fluorescence images of DSNP@A in different pH buffer, FBS and saline solution in the present of $\mathrm{ONOO}^{-}$.

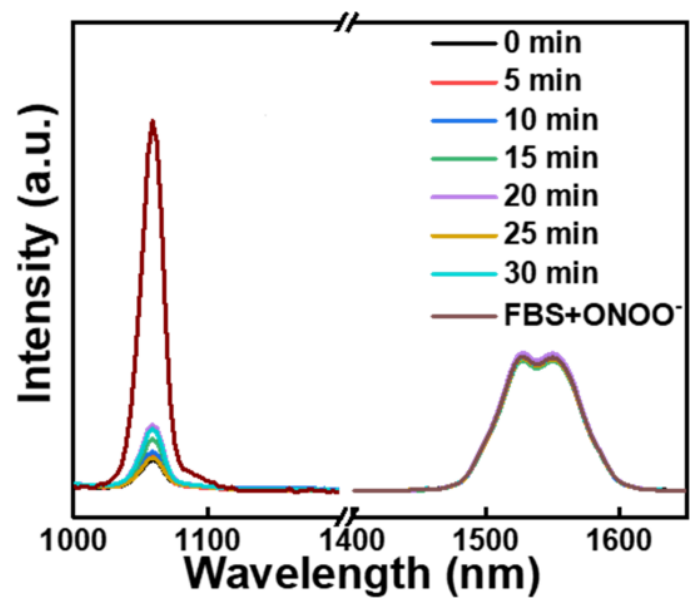

Figure S15. PL spectra of DSNP@A in 10\% FBS under $808 \mathrm{~nm}$ laser irradiation $\left(0.2 \mathrm{~W} \mathrm{~cm}^{-2}\right)$ with different time. As shown in Figure S15, the emission at $1060 \mathrm{~nm}$ exhibited a slight enhancement after exposure for 30 min with $808 \mathrm{~nm}$ laser $\left(0.2 \mathrm{~W} \mathrm{~cm}^{-2}\right)$ caused by the partial destruction of A1094 in DSNP@A, which was neglectable to the increased fluorescence intensity after addition of $\mathrm{ONOO}^{-}$, which verified the feasibility of our DSNP@A as an effective ratiometric nanoprobe. 


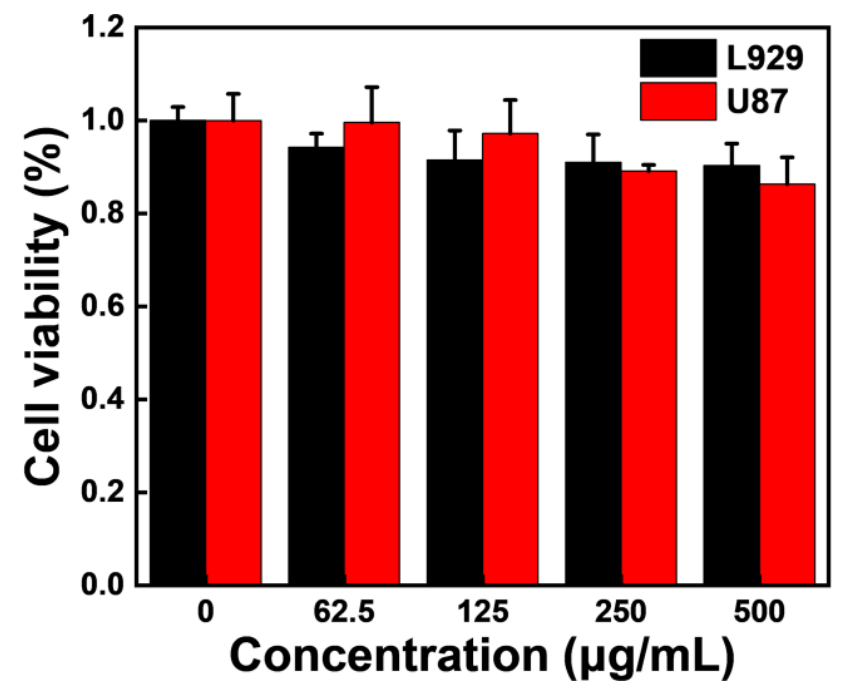

Figure S16. Cytotoxicity assays of L929 and U87 cells treated with different concentration of DSNP@A for 48 h. we carried out the methyl thiazolyl tetrazolium (MTT) method to evaluate the in vitro cytotoxicity of the DSNP@A towards L929 and U87 cells. As shown in Figure S16, the viability of L929 and U87 cells both exceeded over 85\%, even though they were incubated with a high concentration of nanoparticles $(500 \mu \mathrm{g} / \mathrm{mL})$ for $48 \mathrm{~h}$, which demonstrated the excellent biocompatibility of DSNP@A.

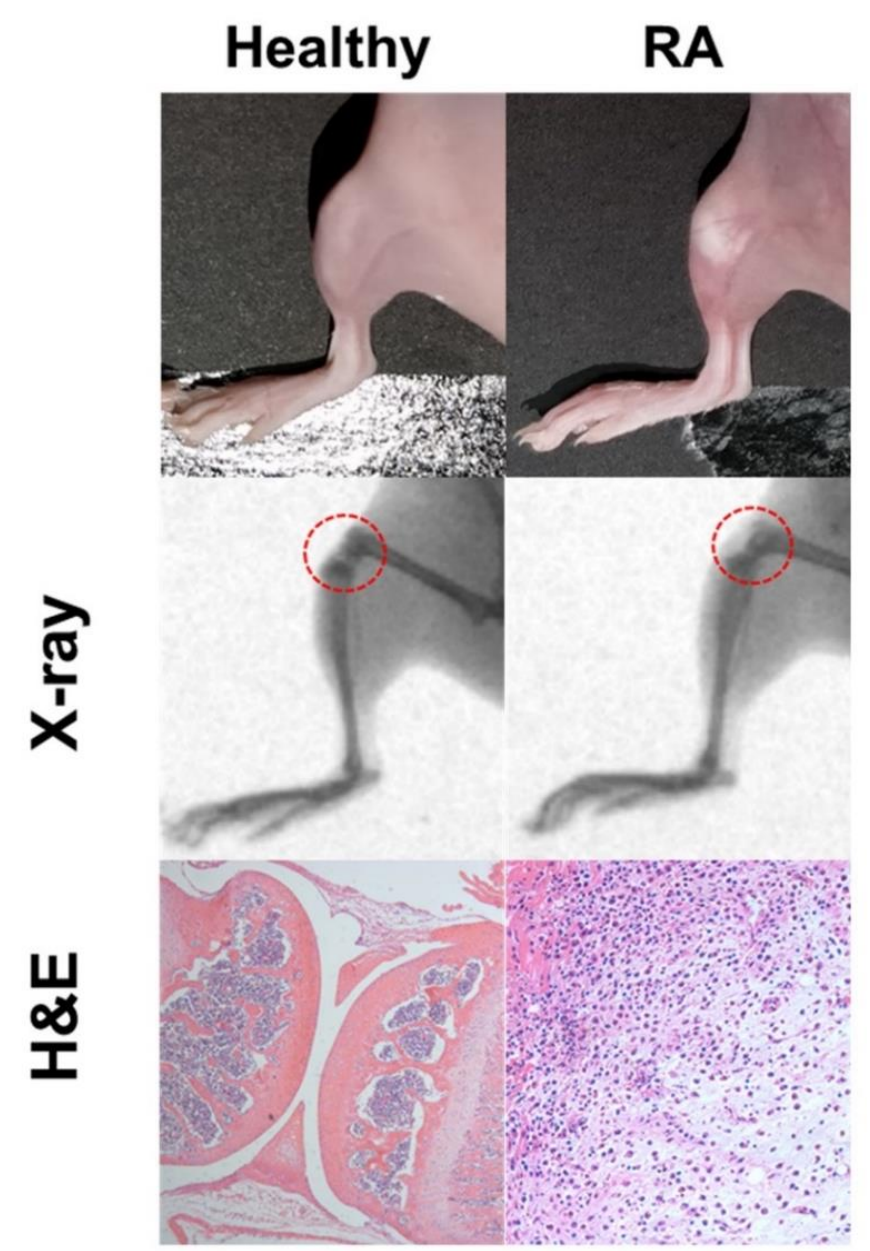

Figure S17. X-ray images and H\&E staining images of the healthy and RA mice. The red dotted cycle is the knee cavity. 
Table S1. The corresponding parameters of fitting curves of $\mathrm{Er}^{3+}$ with different $d_{l}$.

\begin{tabular}{|c|c|c|c|c|c|}
\hline$d_{l}(\mathrm{~nm})$ & $\mathrm{A}_{1}$ & $\tau_{l}(\mu \mathrm{s})$ & $\mathrm{A}_{2}$ & $\tau_{2}(\mu \mathrm{s})$ & $\mathrm{R}^{2}$ \\
\hline 0 & 1 & 60.06 & -- & -- & 0.997 \\
\hline 1.4 & 1 & 180.05 & -- & -- & 0.998 \\
\hline 2.5 & 0.81 & 241.78 & 0.33 & 1379.25 & 0.998 \\
\hline 3.5 & 0.68 & 266.37 & 0.44 & 1637.68 & 0.998 \\
\hline
\end{tabular}

In the case of $d_{1}$ was shorter than $1.4 \mathrm{~nm}$, the PL decay curves were fitted with the monoexponential function ( $\mathrm{I}=\mathrm{A}_{1}$ $\left.\exp \left(-\tau / \tau_{1}\right)+\mathrm{B}\right)$. While it was fitted by biexponential function $\left(\mathrm{I}=\mathrm{A}_{1} \exp \left(-\tau / \tau_{1}\right)+\mathrm{A}_{2} \exp \left(-\tau / \tau_{2}\right)+\mathrm{B}\right)$ when $d_{l}$ was 2.5 and $3.5 \mathrm{~nm}$.

\section{References}

1. Wang, F.; Deng, R.; Liu, X. Preparation of Core-Shell $\mathrm{NaGdF}_{4}$ Nanoparticles Doped with Luminescent Lanthanide Ions to Be Used as Upconversion-Based Probes. Nat. Protoc. 2014, 9, 1634.

2. Li, X.; Shen, D.; Yang, J.; Yao, C.; Che, R.; Zhang, F.; Zhao, D. Successive Layer-by-Layer Strategy for Multi-Shell Epitaxial Growth: Shell Thickness and Doping Position Dependence in Upconverting Optical Properties. Chem. Mater. 2013, 25, 106-112.

3. Tian, M.; Tatsuura, S.; Furuki, M.; Sato, Y.; Iwasa, I.; Pu, L. S. Discovery of Novel Dyes with Absorption Maxima at $1.1 \mu \mathrm{m}$. J. Am. Chem. Soc. 2003, 125, 348-349.

4. Frank, A. W.; Hans, T.; Anders, H.; Pierre, G. Prevention of Joint Destruction in Antigen-Induced Arthritis. Clin. Immunol. Immunopathol.1994, 70, 19-21. 